\title{
Hippocampal lesions and learned taste aversion*
}

\author{
LAWRENCE R. MURPHY and THOMAS S. BROWN \\ DePaul University, Chicago, Illinois 60614
}

\begin{abstract}
Rats with hippocampal lesions were compared with neocortical and sham-operated controls on a taste aversion learning task using an $8 \%$ sucrose solution (CS) and $2 \%$ body weight IP injection of .15 M lithium chloride (UCS). Hippocampally ablated animals acquired the taste aversion as rapidly as controls after a single CS-UCS pairing. No differences were found among the groups in terms of either the magnitude or extinction of the aversion. The results do not support a general loss of response inhibition interpretation of hippocampal function. Rather, the results confirm and extend a number of previous findings indicating that the enhanced perseverative tendencies frequently observed in rats with hippocampal lesions are absent in consummatory-type tasks.
\end{abstract}

Bilateral hippocampal lesions in rats generally produce impairments in test situations where the inhibition of a prepotent or learned response is required. This is evident in the performance of rats with hippocampal lesions in passive avoidance tasks (Kimura, 1958; Isaacson \& Wickelgren, 1962; Kimble, 1963), spontaneous alternation (Roberts, Dember, \& Brodwick, 1962; Dalland, 1970), response patterning (Franchina \& Brown, 1970), discrimination reversal learning (Kimble \& Kimble, 1965), and extinction testing (Niki, 1962; Fried, 1972). Thus the belief that the intact hippocampus functions to generate response inhibition and that its removal results in an enhanced perseverative deficit (Douglas, 1967; Kimble, 1968).

While this is particularly true when such animals are tested in instrumental runway situations, similar impairments are not consistently observed in tasks measuring consummatory responses. Kimble and Coover (1966) found that rats with hippocampal lesions consumed $16 \%-21 \%$ more water postoperatively compared to controls, although later research has not confirmed this result (Boitano, Lubar, Auer, \& Furnald, 1968; Boitano, Abel, Heine, \& Patrissi, 1973). Beatty and Schwartzbaum (1968) reported no heightened reactivity to sucrose, saccharin, or quinine solutions in rats with hippocampal lesions. Similarly, Murphy and Brown (1970) found such animals capable of both increasing and decreasing fluid intake in several consummatory test situations when reinforcement contingencies were altered. It is noteworthy, however, that the magnitude of those adjustments in rats with hippocampal lesions was somewhat less than that observed in control animals. Antelman and Brown (1972) recently found no loss of behavioral inhibition in hippocampally ablated animals in a conditioned suppression paradigm.

In contrast, Miller, Elkins, and Peacock (1971)

*This report is based on a thesis submitted by Lawrence $\mathbf{R}$. Murphy to DePaul University in partial fulfillment of the requirements for the MA degree. The research was supported in part by the State of Illinois Mental Health Fund Grant 290-13-RD to Thomas S. Brown. reported disrupted performance in such animals when a $.1 \%$ saccharin solution was paired with X-irradiation in a taste aversion paradigm. These animals did not show a preference shift following X-irradiation to the degree observed in control animals. Further, Holdstock (1972) found exaggerated licking in rats with posteroventral hippocampal lesions after the drinking tube had been electrified. Holdstock (1972) concluded that the changes in drinking behavior following hippocampal lesions were secondary to a general loss of behavioral inhibition.

The purpose of the present study was to examine the applicability of a perseverative-type disorder to the behavior of rats with hippocampal lesions in a consummatory test situation. To this end, a learned taste aversion paradigm was chosen. In this paradigm, an animal is presented with a distinctively flavored solution (CS) which is conditionally paired with internal sickness (UCS) independently induced via X-irradiation (Revusky, 1968), by injection of lithium chloride (Nachman, 1970), or by use of a drug like apomorphine (Garcia, Ervin, \& Koelling, 1966) or cyclophosphamide (Wilcoxon, Dragoin, \& Kral, 1971). Following future presentations of the CS alone, the normal rat will markedly reduce its intake of this solution after a single CS-UCS pairing (Revusky \& Garcia, 1970). In the rat with a hippocampal lesion, a general loss of behavioral inhibition should impair the acquisition of the taste aversion. That is, such animals should continue to respond to the CS and evidence either no aversion or one that is attenuated.

\section{METHOD}

\section{Subjects}

Forty-eight male Holtzman rats that weighed from 200 to $300 \mathrm{~g}$ were randomly divided into three equal groups of 16 animals each. One group received bilateral hippocampal lesions $(\mathrm{H})$, another neocortical control lesions $(\mathrm{C})$, and a third were sham operated $(\mathrm{N})$. Following surgery, each group was further divided forming one experimental group $(\mathrm{N}=8)$ and one control group $(\mathrm{N}=8)$ for each surgical condition.

\section{Surgery}

Animals were anesthetized with sodium pentobarbital 


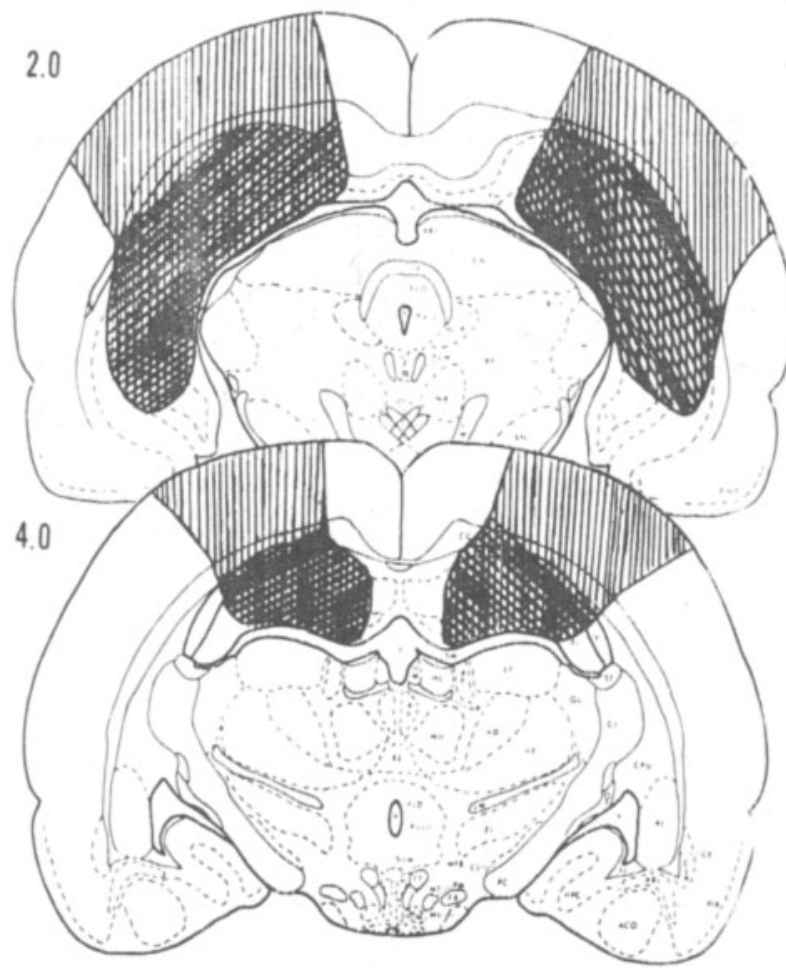

Fig. 1. Reconstruction of representative lesions for $H$ (cross-hatched) and C (striped) groups on plates from the Pellegrino and Cushman (1967) atlas. (Numbers refer to stereotaxic plane of atlas.)

(Nembutal, $40 \mathrm{mg} / \mathrm{kg}$ ) and placed in a headholder. The scalp was incised at midline and holes drilled on either side of the sagittal sinus. For rats in Group $\mathrm{H}$, the cortex overlying the hippocampus was removed exposing the hippocampus. The hippocampus was then aspirated under visual guidance as completely as possible in its dorsal and ventral extent. Group C animals had a similar amount of cortex removed, but the hippocampus was only visualized and not damaged. Animals in Group $\mathrm{N}$ had the skull opened but no damage to the brain itself. For all groups, gelfoam was inserted in the wound to facilitate postoperative clotting and the wound sutured.

\section{Procedure}

For 2 weeks following surgery, all animals were given ad lib access to both food and water. During the latter part of this period, the animals were handled each day for $5 \mathrm{~min}$. Following recovery, adaptation to a $10-\mathrm{min}$ per day drinking regime was initiated for 5 days. During this time, water was restricted while food was available ad lib. Each day the animals were removed from the home cages, weighed, and given access to a tap water solution for $10 \mathrm{~min}$ in a drinking cage similar to the home cage. The amount of fluid consumed was read from a $100-\mathrm{ml}$ graduated drinking tube attached to the front of the drinking cage. On the treatment day ( $\mathrm{Tr}$, Day 6), all animals were given access to an $8 \%$ sucrose solution $(\mathrm{w} / \mathrm{v})$ for the 10 -min period, and the amount consumed was recorded as before. Thirty minutes following the removal of the solution, rats in the experimental groups received a $2 \%$ body weight IP injection of $.15 \mathrm{M}$ lithium chloride $(\mathrm{LiCl})$ solution dissolved in physiological saline (Nachman, 1970). Animals in the control condition were given a similar injection of physiological saline only (placebo). On Days 7 and 8, all animals had access to a tap water solution as before. These days served as recovery days during which time the aversive effects of the injections would dissipate. Avoidance testing began on Day 9 , when all animals were again presented with the $8 \%$ sucrose solution, which was not followed by any injections. The amount of sucrose consumed on this day relative to that consumed on the treatment day served as an index of avoidance responding. This procedure was repeated for 3 additional days (Days 10-12) in order to assess the rate of extinction of the aversion in the experimental animals.

Following completion of the experiment, lesioned animals were sacrificed with an overdose of Nembutal and perfused intracardially with $.9 \%$ saline followed by $10 \%$ Formalin. The brains were removed, embedded in paraffin, and sectioned at 15 microns. Every 10th section through the lesion was mounted and stained according to the method of Klüver and Barrera (1953).

\section{RESULTS}

\section{Histological}

Representative hippocampal and neocortical lesions are shown in Fig. 1. The hippocampal lesions were large and generally uniform in extent. The main source of variability was in the ventral extent, the ventral tips of the hippocampus being intact in most animals. There was some unilateral invasion of the dorsolateral thalamus and posterior septum in some animals, although the damage was slight. In no case was extrahippocampal damage related to performance. The amount of cortex removed tended to be smaller in $\mathrm{H}$ animals relative to those receiving neocortical lesions only. The neocortical lesions sometimes involved damage to the dorsolateral surface of the hippocampus, although in most cases the invasion was unilateral and minimal.

\section{Behavioral}

Table 1 shows the mean amount of fluid consumed in milliliters for $\mathrm{H}, \mathrm{C}$, and $\mathrm{N}$ animals in each treatment condition on each day. Analysis of the data indicated a reliable lesion effect for both water intake $(F=5.90, \mathrm{df}$ $=2,4 \dot{2}, \mathrm{p} \leqslant .001)$ and sucrose intake $(\mathrm{F}=3.49$, df $=$ $2,42, p \leqslant .05)$. In terms of the sucrose intake analysis, the lack of a significant Lesion by Days interaction $(F=$

Table 1

Mean Fluid Consumed (in Milliliters) for Hippocampal (H), Neocortical (C), and Sham Operated (N) Animals in Each Treatment Condition

\begin{tabular}{|c|c|c|c|c|c|c|c|}
\hline \multirow[b]{2}{*}{ Treatments } & \multirow[b]{2}{*}{ Days } & \multicolumn{3}{|c|}{ Experimental } & \multicolumn{3}{|c|}{ Control } \\
\hline & & $\mathbf{H}$ & $\mathrm{C}$ & $\mathrm{N}$ & $\mathrm{H}$ & $\mathrm{C}$ & $\mathrm{N}$ \\
\hline Water & $\begin{array}{l}1 \\
2 \\
3 \\
4 \\
5\end{array}$ & $\begin{array}{r}8.4 \\
12.1 \\
12.5 \\
11.6 \\
12.9\end{array}$ & $\begin{array}{r}7.6 \\
15.0 \\
16.3 \\
16.3 \\
17.1\end{array}$ & $\begin{array}{r}8.3 \\
12.4 \\
14.0 \\
15.4 \\
15.6\end{array}$ & $\begin{array}{r}9.8 \\
11.3 \\
12.3 \\
13.3 \\
13.8\end{array}$ & $\begin{array}{r}8.4 \\
13.8 \\
15.5 \\
15.1 \\
17.0\end{array}$ & $\begin{array}{l}10.3 \\
12.4 \\
14.4 \\
15.8 \\
15.6\end{array}$ \\
\hline $\begin{array}{l}\text { Treatment Day } \\
\text { Sucrose }\end{array}$ & 6 & 22.0 & 25.4 & 23.0 & 18.3 & 24.6 & 21.0 \\
\hline $\begin{array}{l}\text { Recovery Days } \\
\text { Water }\end{array}$ & $\begin{array}{l}7 \\
8\end{array}$ & $\begin{array}{r}9.5 \\
11.9\end{array}$ & $\begin{array}{l}14.9 \\
14.9\end{array}$ & $\begin{array}{l}13.1 \\
14.4\end{array}$ & $\begin{array}{l}12.8 \\
13.3\end{array}$ & $\begin{array}{l}11.6 \\
14.5\end{array}$ & $\begin{array}{l}12.4 \\
14.5\end{array}$ \\
\hline $\begin{array}{l}\text { Test Days } \\
\text { Sucrose }\end{array}$ & $\begin{array}{r}9 \\
10 \\
11 \\
12\end{array}$ & $\begin{array}{r}7.8 \\
13.5 \\
18.0 \\
19.9\end{array}$ & $\begin{array}{r}4.8 \\
12.0 \\
20.1 \\
21.5\end{array}$ & $\begin{array}{r}4.9 \\
13.5 \\
18.9 \\
22.5\end{array}$ & $\begin{array}{l}17.0 \\
17.8 \\
18.8 \\
20.4\end{array}$ & $\begin{array}{l}20.8 \\
22.5 \\
23.4 \\
24.0\end{array}$ & $\begin{array}{l}18.8 \\
19.6 \\
21.6 \\
21.6\end{array}$ \\
\hline
\end{tabular}


$1.47, \mathrm{df}=8,168, \mathrm{p}>.05)$ suggests that the effect was due to a general attenuation of fluid intake in rats with hippocampal lesions and not to differential intakes during avoidance testing. Inspection of Table 1 reveals that rats with hippocampal lesions consumed less fluid than controls throughout the experiment. However, the animals with hippocampal lesions also gained reliably less weight postoperatively compared to controls. This particular observation has been noted previously (Kim et al, 1970; Murphy, Wideman, \& Brown, 1972; Holdstock, 1972). Table 2 gives the mean postoperative weights of $\mathrm{H}, \mathrm{C}$, and $\mathrm{N}$ animals in each treatment condition at the start (Day 1), middle (Day 6), and end (Day 12) of testing. On each sample test day, $\mathrm{H}$ animals weighed reliably less than either $\mathrm{C}$ or $\mathrm{N}$ animals. No differences were found between the latter two groups. Thus, in order to factor out this confounding variable and equate fluid intakes for all groups, absolute fluid intakes were converted to $\mathrm{ml} / 100 \mathrm{~g}$ body weight. The results are expressed as such in Fig. 2. These scores were used in the statistical analyses which follow and will be used in the remainder of this report unless otherwise specified.

A three-way factorial analysis of variance computed on water intake scores (Days 1-5, 7, and 8) indicated no reliable treatment effect $(\mathrm{F}<1)$ nor lesion effect $(\mathrm{F}=$ 2.25 , df $=6,252, \mathrm{p}>.05$ ) but a highly reliable days effect $(F=38.58, d f=6,252, p \leqslant .001)$. This is seen in Fig. 2 as all animals increased their water intake as adaptation to the drinking regime progressed. A reliable decrease in water intake did occur on Day 7 relative to Day $5(\mathrm{R}=2.44$, df $=6, \mathrm{p} \leqslant .05)$ which probably reflects the effects of the injection procedures and intraperitoneal fluid loading on Day 6. Fluid intake increased on Day 8 to a level not reliably different from that on Day 5, indicating a return to preinjection drinking levels in all animals.

A similar analysis was performed on sucrose intake scores on the treatment day ( $\mathrm{Tr}$, Day 6 ) and test days (Test, Days 9-12). The analysis revealed a reliable treatment effect $(\mathrm{F}=25.66, \mathrm{df}=1,42, \mathrm{p} \leqslant .001)$, days effect $(F=72.42$, df $=4,168, p \leqslant .001)$, and Treatment by Days interaction ( $F=46.45, \mathrm{df}=4,168, \mathrm{p} \leqslant .001)$. This is evident in Fig. 2 as experimental animals in each surgical condition markedly reduced fluid intake on Days 9 and 10 relative to that on Day 6. Control group animals showed no such marked reduction. Of primary

Table 2

Mean Postoperative Weights for $\mathrm{H}, \mathrm{C}$, and $\mathrm{N}$ Animals on 3 Sample Test Days

\begin{tabular}{|c|c|c|c|}
\hline & Day 1 & Day 6 & Day 12 \\
\hline $\begin{array}{l}\mathbf{H} \\
\mathrm{C} \\
\mathrm{N}\end{array}$ & $\left.\begin{array}{l}256.0 \\
279.4 \\
296.0\end{array}\right]$ & $\begin{array}{l}242.6 \\
267.8 \\
278.6\end{array}$ & $\left.\begin{array}{l}247.8 \\
276.8 \\
279.0\end{array}\right]$ \\
\hline
\end{tabular}

Note-Brackets connect groups reliably different at .05 level of significance.
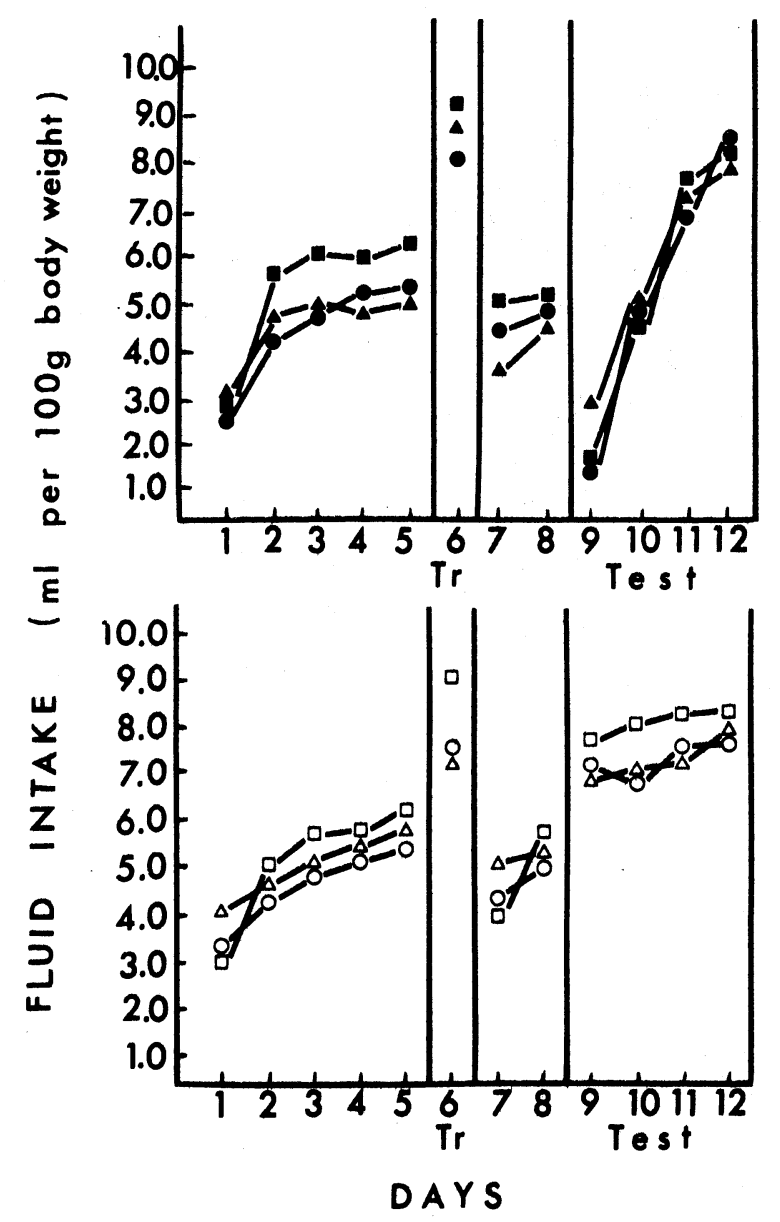

Fig. 2. Mean fluid intake ( $\mathrm{ml} / 100 \mathrm{~g}$ body weight) for $\mathrm{H}$ (triangles), $\mathrm{C}$ (squares), and $\mathrm{N}$ (circles) animals in experimental (top, closed symbols) and control (lower, open symbols) conditions for each day. Sucrose was given on the treatment day (Tr) and test days (Test).

importance in the present study, the lesion effect and all interactions with it did not reach an acceptable level of significance ( $p s>.05$ ). However, there was a tendency for $\mathrm{H}$ animals to drink more of the sucrose solution on the first test day (Day 9) relative to $\mathrm{C}$ or $\mathrm{N}$ animals. The adjusted mean sucrose intake scores for $\mathrm{H}, \mathrm{C}$, and $\mathrm{N}$ animals on Day 9 were $3.13,1.80$, and 1.79 , respectively.

In terms of the conditioning procedure, group means for $\mathrm{H}, \mathrm{C}$, and $\mathrm{N}$ animals were combined and sucrose intake scores on the test days (Days 9-12) were individually compared to that on Day 6 according to Dunnett (1955) for each treatment condition separately. Although sucrose intake was stable across days in control group animals, a highly reliable decrease in sucrose intake did occur in experimental animals on Day $9(\mathrm{t}=9.56, \mathrm{df}=168, \mathrm{p} \leqslant .005)$ and Day $10(\mathrm{t}=$ $5.51, \mathrm{df}=168, \mathrm{p} \leqslant .005)$ but not on Days 11 or 12 . The combined adjusted mean sucrose intake scores for experimental animals on the treatment day and each test day were $8.89,2.24,5.06,7.37$, and 8.25 , respectively. 
Corresponding control group scores were 8.08, 7.34, $7.49,7.73$, and 7.99 , respectively.

\section{DISCUSSION}

The results indicated that animals with hippocampal lesions were similar to controls in terms of adjusted water intake, reactivity to an $8 \%$ sucrose solution, and the acquisition, magnitude, and extinction of a learned taste aversion. These animals showed adequate control over consummatory responding and suffered no apparent loss of response inhibition. Indeed, rats with hippocampal lesions in the present study were able to make fine adjustments in both water intake and sucrose intake. This was characterized by increases (Days 6, 8, and 10-12) and decreases (Days 7 and 9) in fluid intake as reinforcement contingencies were altered. Moreover, the magnitude of these adjustments was similar to that observed in control animals.

The finding that hippocampal lesions in the rat do not impair acquisition or extinction in taste aversion learning (TAL) confirms and extends recent findings by McGowan, Hankins, and Garcia (1972). These authors reported that discrete lesions in either the dorsal or ventral aspects of the hippocampus did not retard the acquisition of a taste aversion relative to controls. The present results extend these findings demonstrating that resistance to extinction in TAL is also unaffected by hippocampal lesions.

However, evidence of disrupted TAL following hippocampal lesions in the rat has been reported (Miller, Elkins, \& Peacock, 1971). In this study, rats with hippocampal lesions failed to show a preference reduction for a $0.1 \%$ saccharin solution which was paired with X-irradiation. Miller et al (1971) attributed the disrupted performance in rats with hippocampal lesions to a basic inability of these animals to withhold a prepotent response. In the context of more recent studies, however, it appears that this is not the case. A more promising hypothesis would emphasize the effects of various procedural parameters on TAL in rats with hippocampal lesions, e.g., test duration and familiarity of test solution.

The demonstration of TAL in rats with hippocampal lesions does not support a prediction of the response perseveration theory. Such a position would predict disrupted performance in such animals when the inhibition of a prepotent or learned response is required. Although TAL requires such behavioral control, rats with hippocampal ablations in the present study were able to control and to adjust consummatory responses as the reinforcement contingencies were changed. Moreover, resistance to extinction was also within normal limits in these animals. The present findings are, therefore, in agreement with the growing body of literature indicating that hippocampal lesions in the rat do not alter or exaggerate consummatory responding (Beatty \& Schwartzbaum, 1968; Boitano, Lubar, Auer,
\& Furnald, 1968; Murphy \& Brown, 1970; Antelman \& Brown, 1972; McGowan, Hankins, \& Garcia, 1972; Boitano, Abel, Heine, \& Patrissi, 1973; Brown \& Murphy, 1973).

The apparent absence of a consummatory-type response impairment in rats with hippocampal lesions indirectly supports the suggestion of Murphy and Brown (1970) that hippocampal lesions in the rat may release certain behavior sequences, such as walking or running, disproportionately to other classes of behavior. Accordingly, one would expect disrupted performance in such animals when the inhibition of a locomotor or gross motor response is required while predicting little or no impairment in consummatory-type tasks. Much additional research is necessary before a fair evaluation of this hypothesis is possible. However, it could be noted at this time that the differential effect of hippocampal lesions on locomotor and consummatory responses nicely parallels the differences reported by Vanderwolf (1969) in the hippocampal EEG of the intact rat when it engages in these diverse classes of behavior.

The formulation of a hypothesis which notes a lesion effect specific to locomotor responses, such as walking or running, appears to provide a new and possibly important framework for future research regarding the functional role of the hippocampus in the rat.

\section{REFERENCES}

Antelman, S. M., \& Brown, T. S. Hippocampal lesions and shuttlebox avoidance behavior: A fear hypothesis. Physiology \& Behavior, 1972, 9, 15-20.

Beatty, W. W., \& Schwartzbaum, J. S. Commonality and specificity of behavioral dysfunctions following septal and hippocampal lesions in rats. Journal of Comparative \& Physiological Psychology, 1968, 66, 60-68.

Boitano, J. J., Abel, H. G., Heine, G. J., \& Patrissi, G. A. Effects of hippocampal lesions on the water consumption of hooded and albino rats. Bulletin of the Psychonomic Society, 1973, 1 , 81-83.

Boitano, J. J., Lubar, J. F., Auer, J., \& Furnald, M. S. Effects of hippocampectomy on consummatory behavior and movement inhibition in rats. Physiology \& Behavior, 1968, 3, 901-906.

Brown, T. S., \& Murphy, H. M. Factors affecting sucrose preference behavior in rats with hippocampal lesions. Physiology \& Behavior, 1973, 11, 833-844.

Dalland, $T$. Response and stimulus perseveration in rats with septal and dorsal hippocampal lesions. Journal of Comparative \& Physiological Psychology, 1970, 71, 114-118.

Douglas, R. J. The hippocampus and behavior. Psychological Bulletin, 1967, 67, 416-442.

Dunnett, C. W. A multiple comparison procedure for comparing several treatments with a control. American Statistical Association, 1955, 50, 1096-1121.

Franchina, J. J., \& Brown, T. S. Response patterning and extinction in rats with hippocampal lesions. Journal of Comparative \& Physiological Psychology, 1970, 70, 66-72.

Fried, P. A. The effect of differential hippocampal lesions and pre- and postoperative training on extinction. Canadian Journal of Psychology, 1972, 26, 61-70.

Garcia, J., Ervin, F. R., \& Koelling, R. A. Learning with prolonged delay of reinforcement. Psychonomic Science, 1966, 5, 121-122.

Holdstock, T. L. Dissociation of function within the hippocampus. Physiology \& Behavior, 1972, 8, 659-667.

Isaacson, R. L., \& Wickelgren, W. C. Hippocampal ablation and passive avoidance. Science, 1962, 138, 1104-1106.

Kim, C., Choi, H.; Kim, J. K., Chang, H. K., Park, R. S., \& Kang, I. Y. General behavioral activity and its component patterns in hippocampectomized rats. Brain Research, 1970, 19, 379-394.

Kimble, D. P. The effects of bilateral hippocampal lesions in rats. Journal of Comparative \& Physiological Psychology, 1963, 56, 273-283.

Kimble, D. P. Hippocampus and behavior. Psychological Bulletin, 1968, 70, 285-295. 
Kimble, D. P \& Coover, G. D. Effects of hippocampal lesion on food and water consumption in rats. Psychonomic Science, 1966, 4, 91-92.

Kimble, D. P., \& Kimble, R. J. Hippocampectomy and response perseveration in the rat. Journal of Comparative \& Physiological Psychology, 1965, 60, 474-476.

Kimura, D. Effects of selective hippocampal damage on avoidance behavior in the rat. Canadian Journal of Psychology, 1958, 12, 213-218.

Klüver, H., \& Barrera, E. A method for the combined staining of cells and fibers in the nervous system. Journal of Neuropathology \& Experimental Neurology, 1953, 12, 400-403.

McGowan, B. K., Hankins, W. G., \& Garcia, J. Limbic lesions and control of the internal and external environment. Behavioral Biology, 1972, 7, 841-852.

Miller, C. R., Elkins, R. L., \& Peacock, L. J. Disruption of a radiation-induced preference shift by hippocampal lesions. Physiology \& Behavior, 1971, 6, 283-285.

Murphy, H. M., \& Brown, T. S. Effects of hippocampal lesions on simple and preferential consummatory behavior in the rat. Journal of Comparative \& Physiological Psychology, 1970, 72 , 405-415.

Murphy, H. M., Wideman, C. H., \& Brown, T. S. Liver glycogen levels in rats with limbic lesions. Physiology \& Behavior, 1972 $8,1171-1174$

Nachman, $M$. Learned taste and temperature aversions due to lithium chloride sickness after temporal delays. Journal of Comparative \& Physiological Psychology, 1970, 73, 22-30.

Niki, H. The effects of hippocampal ablation on the behavior in the rat. Japanese Psychological Research, 1962, 4, 139-153.

Pellegrino, L. J., \& Cushman, A. J. A stereotaxic atlas of the rat brain. New Y ork: Appleton-Century-Crofts, 1967.

Revusky, S. H. Aversion to sucrose produced by contingent X-irradiation. Journal of Comparative \& Physiological Psychology, 1968, 65, 17-22.

Revusky, S. H \& Garcia, J Learned associations over long delays. In G. H. Bower and J. T. Spence (Eds.), The psychology of learning and motivation, IV. New York: Academic Press, 1970.

Roberts, W. W., Dember, W. W., \& Brodwick, M. Alternation and exploration in rats with hippocampal lesions. Journal of Comparative \& Physiological Psychology, 1962, 55, 695-700.

$V$ anderwolf, C. H. Hippocampal electrical activity and voluntary movement in the rat. Electroencephalography \& Clinical Neurophysiology, 1969, 26, 407-418.

Wilcoxon, H. C., Dragoin, W. B., \& Kral, P. A. Illness-induced aversions in rat and quail: Relative salience of visual and gustatory cues. Science, 1971, 171, 826-828.

(Received for publication July 25,1973 ; revision received November $12,1973$. ) 